\title{
High Cadmium Levels in Cured Meat Products Marketed in Nigeria - Implications for Public Health
}

\author{
Olufunmilayo E Adejumo ${ }^{1 *}$, Pius S Fasinu ${ }^{2}$, Judith E Odion ${ }^{1}$, Boladale O Silva ${ }^{3}$, \\ Timothy O Fajemirokun ${ }^{4}$
}

\begin{abstract}
Heavy metals are known to disrupt important physiological processes in living cells, and have been responsible for various pathological conditions with possible contributions to cancer development. Food contamination have been identified as one of the ways humans are exposed to heavy metals. In developing countries like Nigeria, the regulatory framework for enforcing compliance with globally acceptable exposure to deleterious contaminants is poor. In the current study, thirteen samples of cured meat products of diverse origin marketed in South-west Nigeria were evaluated for lead, cadmium, chromium and nickel contents using the atomic absorption spectroscopy technique. All the samples analysed contained cadmium between 0.35 and $1.20 \mathrm{ppm}$, levels considered higher than acceptable limits in consumable products. Lead, chromium and nickel were not detected in any of the samples. As known cumulative poisons, there is the need for stringent regulatory control of these heavy metals in cured meat products imported into or produced indigenously in the country in order to minimize the risks to public health.
\end{abstract}

Keywords: AAS - cadmium levels - elemental impurities - heavy metals - meat products - Nigeria - public health

Asian Pac J Cancer Prev, 17 (4), 1933-1936

\section{Introduction}

Cadmium, a naturally occurring metal with an abundance of approximately 0.15 ppm in the Earth's crust, is a well-known carcinogen (Rahim et al., 2013; Demir et al., 2014). Found in low level in soils and rocks, its commercial use in electrical, metallurgical and plastic industries, coupled with its environmental pollution through the smelting of other metals and burning of fossil fuel, increase its human exposure (Fasinu and Orisakwe, 2013). Cadmium inhaled or consumed in contaminated products accumulate in human body with very slow elimination (half-life is 10 - 30 years) causing initial toxicity to the kidney. While no physiological benefit is attributed to cadmium in humans, its ability to disrupt biological processes is well documented.

Besides carcinogenicity, cadmium alters cell adhesion processes, inhibits apoptosis and modulates the DNA repair system (Nemmiche et al., 2011; Chen et al., 2014; Chen et al., 2015; Bishak et al., 2015). The ability of cadmium to substitute for zinc in physiologic reactions including the synthesis of RNA, DNA and essential enzymes enhances its destructive activity to the cells (Golovine et al., 2010). Long term exposure to cadmium has thus been associated with various pathological conditions including pulmonary dysfunction, bone demineralization, and cancers of the lung, prostate and kidneys (Nair et al., 2013).

The International Agency for Research on Cancer (IARC), a scientific organization that serves as the WHO's source of information on cancer, has classified cadmium and its compounds as a Class I carcinogen, the highest class that indicates the availability of sufficient scientific evidence of carcinogenicity to humans with a clear understanding of the relevant mechanism (IARC Monograph 58 and $100 \mathrm{C}, 2012$ ). It is based on this knowledge that the levels of cadmium and other heavy metals in food, water and the habitable environment are globally monitored and regulated.According to the United States Environmental Protection Agency (USEPA), the maximum permissible cadmium contamination levels in air, soil, agricultural products, drinking water and water that support aquatic life are 100-200 $\mu \mathrm{g} / \mathrm{L}, 85 \mu \mathrm{g} / \mathrm{kg}, 5$ $\mu \mathrm{g} / \mathrm{L}, 5 \mu \mathrm{g} / \mathrm{L}$ and $8 \mu \mathrm{g} / \mathrm{L}$ respectively (http://www.epa. gov; Duruibe et al., 2007).

Like cadmium, lead, chromium and nickel are not known to have any beneficial effects in living cells, and have all been shown to induce deleterious pathologies including cancer in humans (Abdel et al., 2015; Lin et al., 2015).

Nigeria, with an estimated population of 160 million 
Table 1. Characteristics of Sampled Cured Meat Products

\begin{tabular}{lccccccc}
\hline Sample & Description & Batch No. & Origin & DOM & DOE & DOP & Cadmium $(\mathrm{mg} / \mathrm{kg})$ \\
\hline A & Corned Beef & 311790L3 & Argentina & $08 / 2009$ & $08 / 2014$ & $29 / 03 / 2010$ & 0.35 \\
B & Corned beef & DIPOA0078/76 & England & $10 / 2007$ & $10 / 2012$ & $19 / 03 / 2010$ & 0.38 \\
C & Corned beef & FR65286002CE & France & $06 / 2009$ & $06 / 2014$ & $16 / 03 / 2010$ & 0.70 \\
D & Ham & NL129EG & Holland & Nil & $12 / 2012$ & $22 / 03 / 2010$ & 0.81 \\
E & Beef-Luncheon & NSCECI & Brazil & $23 / 04 / 09$ & $10 / 2010$ & $19 / 03 / 2010$ & 1.01 \\
F & Hot-Dogs & FRIBOI-85467-1 & UK & $05 / 07$ & $05 / 2011$ & $19 / 03 / 2010$ & 0.67 \\
G & Cocktail-sausages & NL153EG & Holland & $10 / 2009$ & $10 / 2010$ & $19 / 03 / 2010$ & 0.88 \\
H & Minced-beef & UKR021EC & UK & Nil & $07 / 2011$ & $19 / 03 / 2010$ & 0.69 \\
I & Bacon & NL129EG & Holland & $12 / 2007$ & $02 / 2013$ & $22 / 03 / 2010$ & 0.59 \\
J & Luncheon-Meat & CICNCI & Holland & $09 / 02 / 2009$ & $09 / 02 / 2013$ & $22 / 03 / 2010$ & 0.85 \\
K & Sausage-Roll & 15/60-0P-026 & Nigeria & $04 / 2010$ & $04 / 2010$ & $19 / 04 / 2010$ & 0.90 \\
L & Meaty-Sausage & FT-1514 & Nigeria & $04 / 2010$ & $04 / 2010$ & $19 / 04 / 2010$ & 1.20 \\
M & Hamburger & Nil & Nigeria & $04 / 2010$ & $04 / 2010$ & $19 / 04 / 2010$ & 0.87 \\
\hline
\end{tabular}

$\mathrm{DOM}=$ Date of manufacture, $\mathrm{DOE}=$ Date of expiry, $\mathrm{DOP}=$ Date of purchase; Lead, nickel and chromium were not detected in any of the samples

is the most populous country in Africa. Like most other developing countries, the regulatory framework with regards to heavy metal contamination is poor. Cured meat products which are mostly imported from other countries form part of the diet of a large percentage of the population. Besides possible contamination during the processing, cured meat are exposed to contamination through packaging methods and types. The freedom of such imported products from heavy metals such as lead, cadmium, nickel and chromium are not ascertained before they reach the consuming public.

Various analytical methods such as electrochemical techniques based on amperometry, electrochemical stripping analysis (Attar et al., 2015); atomic absorption spectrometry (AAS) including flame and electrothermal atomic absorption spectrometry, inductively coupled plasma atomic emission spectrometry and inductively coupled plasma mass spectrometry (Davidson, 2013); spectrophotometric-AAS (Khazaeli et al., 2013) and high performance liquid chromatography (HPLC) have been employed in detecting and quantifying heavy metals in seed oils, cigarettes, soils and meat products (Khemnani et al, 2012; Demirel et al., 2013; Soylak et al., 2013).

The aim of the current study was therefore to determine the level of selected heavy metals in various commercial meat products in Nigeria using the atomic absorption spectrometric technique, and comparing the results to globally acceptable standards.

\section{Materials and Methods}

\section{Materials}

Samples comprising corned beef, ham, bacon, luncheon meat and sausages were randomly purchased from supermarkets, fast-food restaurants and open markets in South-west Nigeria. They were immediately labelled and frozen at $-20^{\circ} \mathrm{C}$ in prewashed polythene bags till time of analysis. All flasks and glassware used were rigorously washed and rinsed with deionized water. The reagents used were of analytical grade and all solutions were prepared with deionized water.

\section{Method}

Samples were separately weighed $(1.0 \mathrm{~g})$ into $50 \mathrm{~mL}$ digestion tubes and digested with $\mathrm{H}_{2} \mathrm{SO}_{4}$ /selenium mixture ( $2.5 \mathrm{~mL}$ ). Using laboratory hot plates, the sample $/ \mathrm{H}_{2} \mathrm{SO}_{4} /$ selenium mixtures were heated at $200^{\circ} \mathrm{C}$ until fumed. This was followed by cooling $(1 \mathrm{~h})$ and the sequential addition of $30 \% \mathrm{H}_{2} \mathrm{O}_{2}(1 \mathrm{~mL}$ first, then $2 \mathrm{~mL})$ to each sample and control allowing $10 \mathrm{~min}$ in-between for interactions and reactions. The resultant mixtures were again separately placed on the hotplate and left for $2 \mathrm{~h}$ until the yellow tint of the samples disappeared as the digestion was completed. Digested samples were allowed to cool to room temperature, filtered with glass wool and diluted to $50 \mathrm{~mL}$ mark with distilled deionized water. The samples were then analysed for cadmium, lead, chromium and nickel content on a Buck 200A atomic absorption spectrophotometer. Blanks and calibration standard solutions were similarly analysed as the samples. Elemental analysis on the absorption spectrometer had earlier been optimized with satisfactory recovery and results.

\section{Results}

Cadmium contents of the samples ranged from 0.35$1.20 \mathrm{mg} / \mathrm{kg}$ with a mean concentration of $0.76 \pm 0.23$ (median=0.81). Table 1 provides the characteristics of sampled cured meat products and their heavy metal contents respectively. Lead, chromium and nickel were not detected in any of the samples. Comparison of this result with limits given by the European Commission Regulation (ECR), USEPA and the United States Food and Drug Agency (USFDA) revealed all samples ( $n=13,100 \%)$ had cadmium levels exceeding the maximum permissible limit (MPL) of $50 \mu \mathrm{g} / \mathrm{kg}$ in consumable products.

\section{Discussion}

This study was able to evaluate the heavy metal content of sampled imported meat products in Nigeria. The maximum allowed concentrations of elemental impurities of lead, cadmium, chromium and nickel in meat in $\mathrm{mg} / \mathrm{kg}$ are $0.1,0.005,1.0$, and 0.1 respectively (USFDA, 2006; OJEC, 2001; European Commission Regulation, 2006). Results from this study showed that lead, chromium and nickel were not present in detectable amounts in any of the samples while cadmium content ranged between 0.35 
and $1.20 \mathrm{mg} / \mathrm{kg}$. This level is dangerously high and raised concerns on health hazards to the meat consumers.

According the US Environmental protection agency, and the Agency for Toxic Substances and Disease Registry (ATSDR), the provisional tolerable daily intake for cadmium is $1 \mu \mathrm{g} / \mathrm{kg}$ of body weight (Center for Disease Control, 2011). For a 70-kg man, this translates to a daily consumption of cadmium not exceeding $70 \mu \mathrm{g}$. From the current study where the mean cadmium concentration in the sampled meat products was $0.76 \mathrm{mg} / \mathrm{kg}(0.76 \mu \mathrm{g} / \mathrm{g})$, the consumption of a 100 gram of the assessed samples exposes the consumers to cadmium levels higher than recommended.

Cadmium is a cumulative poison characterized by accumulation in major body organs especially the kidneys, liver and lungs (Goyer. 1991; Nordberg, 1985). Acute effects of cadmium poisoning include throat dryness, cough, headache, vomiting, chest pain, extreme restlessness and irritability, pneumonitis, bronchopneumonia and death due to severe lung damage. Gastrointestinal absorption of cadmium is about 5 to $8 \%$. Thus, the consumption of cadmium-contaminated food or water increases salivation, severe stomach irritation, vomiting and diarrhoea (Baker and Hafner, 1961; Buckler et al., 1986).

The level of cadmium contamination of the samples analysed in this study consequently presents public health and safety concerns. Previous reports have also shown that prolonged intake of cadmium polluted samples may result in chronic toxicity which could manifest as chronic renal tubular disease, secondary hyperthyroidism, decreased contractile ability of the heart, neoplastic disease and osteoporosis (Roschnik, 1973). An epidemiological study of the dose-response relationship of cadmium intake revealed that a daily intake in food of 0.14 to $0.26 \mathrm{mg}$ of cadmium per day for more than 50 years produced renal dysfunction since cadmium is excreted primarily in the urine. The cadmium content of the samples in this study was found to be 2-9 times these values. Further, acute oral dose exposure of 20-30 g reportedly has caused fatalities in humans while exposure to lower amounts may cause GI irritation, vomiting, abdominal pain, and diarrhoea (ATSDR, 1989; DeStefano et al, 2010). Cadmium, mercury, and lead poisoning have equally been reported in herbal products used in Brazil (Caldas et al, 2004) and higher cadmium concentration have been found in aerial plant parts than in the roots (Cooper et al., 2007).

For developing countries like Nigeria, where public health concerns are shifting to non-communicable diseases, with urban affluence that is dependent on imported food products, it is important to regulate heavy metal contamination in consumable products. This study has revealed that preventable exposure to heavy metals through imported food product is prevalent and might not have caught the attention of public health policy makers. There is therefore, a need for strict monitoring of cured meat products in other to prevent or at least greatly minimize exposure of consumers to these pollutants.

In conclusion, all the meat samples assessed in this study contained cadmium contaminant at concentrations far exceeding the internationally permitted levels. This high cadmium contamination presents public health and safety concerns. Consequently, regulatory agencies should ensure stringent control of elemental impurities particularly cadmium content in cured meat products that are imported into or produced indigenously in Nigeria in order to minimize their risks to public health. Further, this study contributes to upcoming studies for the determination and setting of standards for heavy metal concentration for food products like cured meat in Nigeria.

\section{References}

Abdel Aziz AM, Sh Hamed S, Gaballah MA (2015). Possible relationship between chronic telogen effluvium and changes in lead, cadmium, zinc, and iron total blood levels in females: a case-control study. Int J Trichol, 7, 100-6

ATSDR (1989). Toxicological Profile for Cadmium. Atlanta, Ga: Public Health Service Agency

Attar A, Ghica ME, Amine A, Brett CM (2015). Comparison of cobalt hexacyanoferrate and poly (neutral red) modified carbon film electrodes for the amperometric detection of heavy metals based on glucose oxidase enzyme inhibition. Analytical Letters, 48, 659-71.

Baetz RA, Kenner CT (1973). Determination of heavy metals in foods. J Agric Food Chem, 21, 436

Baker TD and Hafner WG (1961). Cadmium poisoning from a refrigerator shelf used as an improvised barbecue grill. Public Health Report, 76, 543-4.

Bishak YK, Payahoo L, Osatdrahimi A, Nourazarian A (2015). Mechanisms of cadmium carcinogenicity in the gastrointestinal tract. Asian Pac J Cancer Prev, 16, 9-21

Buckler HM, Smith WD and Rees W. 1986. Self-poisoning with oral cadmium chloride. Br Med J, 292, 1559-60.

Caldas ED, Machado LL (2004). Cadmium, mercury and lead in medicinal herbs in Braz. Food Chem Toxicol, 42, 599-603

Center for Disease Control (2011). http://www.atsdr.cdc.gov/ csem/csem.asp?csem $=6 \& p o=7$

Chen CY, Zhang SL, Liu ZY, Tian Y, Sun Q (2015). Cadmium toxicity induces ER stress and apoptosis via impairing energy homoeostasis in cardiomyocytes. Biosci Rep, 35, 214.

Chen YY, Zhu JY, Chan KM (2014). Effects of cadmium on cell proliferation, apoptosis, and proto-oncogene expression in zebrafish liver cells. Aquat Toxicol, 157, 196-206

Cooper K, Noller D, Connel D, et al (2007). Public health risks from heavy metal and metalloids present in traditional Chinese medicines. J Toxicol Env Health A, 70, 1694-9

Davidson CM. 2013. Methods for the Determination of Heavy Metals and Metalloids in Soils. Environ Pollution, 22, 97-140

Demir N, Enon S, Turksoy VA et al (2014). Association of cadmium but not arsenic levels in lung cancer tumor tissue with smoking, histopathological type and stage. Asian Pac J Cancer Prev, 15, 2965-70.

Demirel B, Gol NP, Onay TT (2013). Evaluation of heavy metal content in digestate from batch anaerobic co-digestion of sunflower hulls and poultry manure. J Mater Cycles Waste Manage, 15, 242-6.

DeStefano AJ, Zaidi K, Cecil TL, Giancaspro GI and the USP Elemental Impurities Advisory Panel (2010). Elemental Impurities-Information in the United States Pharmacopeial Convention, Inc. Pharmacopeial Forum, 36, 1-9

Duruibe JO, Ogwuegbu MOC, Egwurugwu JN (2007). Heavy metal pollution and human biotoxic effects. Int J Phys Sci, 2, 112-8.

European Commission Regulation 2006. No 1881|2006. Setting maximum levels for certain contaminants in foodstuffs. 
Fasinu PS, Orisakwe OE (2013). Heavy metal pollution in sub-Saharan Africa and possible implications in cancer epidemiology. Asian Pac J Cancer Prev, 14, 3393-402.

Golovine K, Makhov P, Uzzo RG, et al (2010). Cadmium downregulates expression of XIAP at the post-transcriptional level in prostate cancer cells through an NF-kappaB-independent, proteasome-mediated mechanism. Mol Cancer $\mathbf{9 , 1 8 3}$.

Goyer RA (1991). Transplacental transfer of cadmium and foetal effects. Fund Appl Toxicol, 16, 22-3.

Khazaeli S, Nezamabadi N, Rabani M, Panahi HA (2013).. A new functionalized resin and its application in flame atomic absorption spectrophotometric determination of trace amounts of heavy metal ions after solid phase extraction in water samples. Microchem J, 106, 147-153.

Khemnani S, Aswani B, Arora A, Sindal RS. 2012. Detection of heavy metal contents in the seed oil of solanum malongena (eggplant) of arid zone. Int J Basic Appl Chem Sci, 2, 59-65

Lin SC, Singh K, Lin SC. (2015). Association between body levels of trace metals and glaucoma prevalence. JAMA Ophthalmol, 133, 1144-50.

Nair AR, Degheselle O, Smeets K, Van Kerkhove E, Cuypers A (2013). Cadmium-Induced Pathologies: Where Is the Oxidative Balance Lost (or Not)? Int J Mol Sci 14: 6116-43

Nemmiche S, Chabane-Sari D, Kadri M, Guiraud P. 2011. Cadmium chloride-induced oxidative stress and DNA damage in the human Jurkat $\mathrm{T}$ cell line is not linked to intracellular trace elements depletion. Toxicol In Vitro 25: 191-8

Nordberg GF, Kjellstrom T and Nordberg M (1985). Kinetics and metabolism. In: Friberg L, Elinder CG, Kjellstro“m T, et al., eds. Cadmium and Health: A Toxicological and Epidemiological Appraisal. Vol. I. Exposure, Dose, and Metabolism. Boca Raton, FL: CRC Press, 103-78

Rahim F, Jalali A, Tangestani R (2013). Breast cancer frequency and exposure to cadmium: a meta- analysis and systematic review. Asian Pac J Cancer Prev, 14, 4283-7

Roschnik RK. 1973. The determination of lead and cadmium in foods by atomic absorption spectrophotometry. Analyst 98, 596.

Soylak M, Cihan Z, Yilmaz E (2013). Heavy metal contents of organically produced, harvested, and dried fruit samples from Kayseri, Turkey. Environmental Monitor Assess, 185, 2577-83.

USDA (2006). Foreign agricultural service GAIN report global agriculture information network voluntary report-public distribution GAIN report number CH 6064, China Peoples Republic of FAIRS Product. Specific Maximum Levels of Contaminants in Foods, Jim Butterworth and Wu Bugang. 